\title{
Characterization of a Y-Family DNA Polymerase eta from the Eukaryotic Thermophile Alvinella pompejana
}

\author{
Sayo Kashiwagi, ${ }^{1}$ Isao Kuraoka, ${ }^{1}$ Yoshie Fujiwara, ${ }^{1}$ Kenichi Hitomi, ${ }^{1,2,3}$ Quen J. Cheng, ${ }^{3,4}$ \\ Jill O. Fuss, ${ }^{3}$ David S. Shin, ${ }^{2,3}$ Chikahide Masutani, ${ }^{5}$ John A. Tainer, ${ }^{2,3}$ Fumio Hanaoka, ${ }^{6}$ \\ and Shigenori Iwai ${ }^{1}$
}

${ }^{1}$ Graduate School of Engineering Science, Osaka University, 1-3 Machikaneyama, Toyonaka, Osaka 560-8531, Japan

${ }^{2}$ Department of Molecular Biology and The Skaggs Institute for Chemical Biology, The Scripps Research Institute, La Jolla, CA 92037, USA

${ }^{3}$ Life Science Division, Lawrence Berkeley National Laboratory, Berkeley, CA 94720, USA

${ }^{4}$ University of California San Diego, 9500 Gilman Drive no. 0613C, La Jolla, CA 92093, USA

${ }^{5}$ Graduate School of Frontier Biosciences, Osaka University, 1-3 Yamadaoka, Suita, Osaka 565-0871, Japan

${ }^{6}$ Faculty of Science, Gakushuin University, 1-5-1 Mejiro, Toshima-ku, Tokyo 171-8588, Japan

Correspondence should be addressed to Shigenori Iwai, iwai@chem.es.osaka-u.ac.jp

Received 13 May 2010; Accepted 29 June 2010

Academic Editor: Ashis Basu

Copyright (C) 2010 Sayo Kashiwagi et al. This is an open access article distributed under the Creative Commons Attribution License, which permits unrestricted use, distribution, and reproduction in any medium, provided the original work is properly cited.

\begin{abstract}
Human DNA polymerase $\eta$ (HsPol $\eta$ ) plays an important role in translesion synthesis (TLS), which allows for replication past DNA damage such as UV-induced cis-syn cyclobutane pyrimidine dimers (CPDs). Here, we characterized ApPol $\eta$ from the thermophilic worm Alvinella pompejana, which inhabits deep-sea hydrothermal vent chimneys. ApPol $\eta$ shares sequence homology with HsPol $\eta$ and contains domains for binding ubiquitin and proliferating cell nuclear antigen. Sun-induced UV does not penetrate Alvinella's environment; however, this novel DNA polymerase catalyzed efficient and accurate TLS past CPD, as well as 7,8-dihydro-8oxoguanine and isomers of thymine glycol induced by reactive oxygen species. In addition, we found that ApPol $\eta$ is more thermostable than $\mathrm{HsPol} \eta$, as expected from its habitat temperature. Moreover, the activity of this enzyme was retained in the presence of a higher concentration of organic solvents. Therefore, ApPol $\eta$ provides a robust, human-like Pol $\eta$ that is more active after exposure to high temperatures and organic solvents.
\end{abstract}

\section{Introduction}

Although genomic DNA contains genetic information that should be error-free for proper cellular function, it is continually subjected to ubiquitous DNA-damaging agents of both environmental and endogenous origins, such as UV and ionizing radiation and reactive oxygen species (ROS) [13]. To maintain genomic integrity, cells possess several repair pathways, including nucleotide excision repair (NER), base excision repair (BER), and recombination repair, to cope with the various resulting lesions. However, some lesions are not repaired and are encountered by the replication machinery. During DNA replication, these lesions block highfidelity replicative DNA polymerases, and if not processed correctly, eventually lead to mutagenesis, carcinogenesis, or cell death. To avoid such catastrophic consequences, cells have a translesion DNA synthesis (TLS) mechanism that allows efficient and accurate DNA synthesis past lesions [46].

The importance of TLS in humans has been indicated by studies of an inherited human disease called xeroderma pigmentosum variant $(\mathrm{XP}-\mathrm{V})$, which is characterized by the hypersensitivity of skin to sunlight and the high incidence of sunlight-induced skin cancer $[7,8]$. The $X P V$ gene encodes human DNA polymerase $\eta$ (HsPol $\eta$ ), a 713 amino acid protein that is a member of the Y-family DNA polymerases that includes human DNA polymerases $l, \kappa$, and $\operatorname{Rev} 1[6,9$, 10]. Cells from XP-V patients are defective in the replication of damaged DNA and show hypermutability after exposure to UV radiation or DNA-damaging agents. These results 
indicate that HsPol $\eta$ is at least involved in the accurate translesion pathway to avoid mutations by UV-induced lesions in vivo. Consistent with these observations, biochemical studies revealed that $\mathrm{HsPol} \eta$, unlike the replicative Pol $\delta$ and Pole, was able to catalyze efficient and accurate TLS past a UV-induced cis-syn cyclobutane pyrimidine dimer (CPD). In contrast, DNA containing other UV-induced lesions, such as the pyrimidine (6-4)pyrimidone photoproduct (6-4 pp) and its Dewar valence isomer (Dewar), which are efficiently repaired by NER in vivo $[11,12]$, is not replicated by HsPol $\eta$ $[13,42]$.

Furthermore, this enzyme was reportedly able to bypass not only UV-induced lesions but also various other lesions induced by both environmental and endogenous reactive oxygen species. For instance, HsPol $\eta$ bypasses 7,8-dihydro8-oxoguanine (8-oxoG), 5R-thymine glycol (5R-Tg), and $5 S$ thymine glycol (5S-Tg), but not an apurinic/apyrimidinic (AP) site [13-19], although these lesions, which have small alterations in their chemical structures, are mainly repaired by BER in vivo. Thus, these findings indicate that $\mathrm{HsPol} \eta$ also plays an important function in the replication of DNA containing ROS-induced lesions in vivo.

In addition to its role in TLS, HsPol $\eta$ can extend DNA synthesis from D-loop recombination intermediates, and its activity is stimulated by Rad51 recombinase [20]. Moreover, Pol $\eta$-disrupted DT40 cells show significant decreases in the frequencies of both immunoglobulin-variable gene conversion and double-strand break-induced homologous recombination [21]. Taken together, these reports indicate that $\mathrm{Pol} \eta$ is involved in homologous recombination repair, and thus, Pol $\eta$ seems to be important for DNA damage tolerance in living cells.

Alvinella pompejana is a polychaetous annelid that inhabits active deep-sea hydrothermal vent sites along the East Pacific Rise, where it colonizes the walls of actively venting high-temperature chimneys. The average temperature is about $68^{\circ} \mathrm{C}$, with spikes up to $81^{\circ} \mathrm{C}$, and thus exceeds the predicted $55^{\circ} \mathrm{C}$ limit for the survival of eukaryotes [22, 23]. The ability of this worm to survive in such an extreme environment suggests that $A$. pompejana may contain highly stable proteins that can be used for biology, biotechnology, and industry. Several proteins have been characterized from A. pompejana and the analyses have revealed the proteins have enhanced thermostability [24-26], which include $A$. pompejana superoxide dismutase (SOD) and U2AF65, which are more stable than their human homologs.

In this study, we cloned an A. pompejana gene with homology to the HsPol $\eta$ gene. The encoded full-length recombinant protein was produced in Escherichia coli. Characterization of ApPol $\eta$ revealed that it had the ability to bypass CPD, 8-oxoG, $5 R-\mathrm{Tg}$, and $5 S$-Tg, but did not bypass either 6-4 pp, Dewar, or an AP site analog. This substrate specificity is similar to that of the HsPol $\eta$, yet ApPol $\eta$ is comparatively more thermostable than HsPol $\eta$ and retains activity in the presence of organic solvents. Therefore, ApPol $\eta$ is a robust human-like Pol $\eta$ that is useful to complement and expand ideas on TLS mechanisms by virtue of its eukaryotic origin and enhanced stability.

\section{Materials and Methods}

2.1. Materials. Recombinant HsPol $\eta$ tagged with (His) ${ }_{6}$ at its C-terminal end was produced in Sf9 insect cells using the baculovirus expression system and was purified by sequential column chromatography on HiTrap Q, Ni-NTA agarose, and MonoS, as described previously [17]. Klenow fragment $3^{\prime}-5^{\prime}$ exonuclease minus (KF) and T7 DNA polymerase were purchased from New England Biolabs and USB, respectively. Oligonucleotides containing CPD [27], 6-4 pp [28], Dewar [29], 5R-Tg [30], and 5S-Tg [31] were synthesized on an Applied Biosystems 3400 DNA synthesizer, as described, and those containing 8-oxoG and the AP site analog (dSpacer) were synthesized using phosphoramidite building blocks purchased from Glen Research.

2.2. Cloning of the ApPoln Gene. Full-length ApPol $\eta$ cDNA was isolated by RACE PCR, using cDNA prepared with the GeneRacer kit (Invitrogen) from total RNA isolated from frozen whole worm samples. A $2.5 \mathrm{~cm}$ frozen section of the posterior end of $A$. pompejana collected with the DSV Alvin submersible [23] was ground using a mortar and pestle in liquid nitrogen. The ground tissue was aliquoted into eppendorf tubes, and after the addition of Trizol (Invitrogen) $(1.4 \mathrm{~mL})$, the mixture was incubated at room temperature for 10 minutes. After centrifugation at $12,000 \times \mathrm{g}$ for 10 minutes, the supernatant $(1 \mathrm{~mL})$ was mixed with chloroform $(250 \mu \mathrm{l})$, and was incubated at room temperature for 2 minutes. The samples were then centrifuged at $12,000 \times \mathrm{g}$ for 15 minutes to separate the total RNA into the aqueous layer. The RNA was then precipitated by adding isopropanol $(500 \mu \mathrm{l})$ to the aqueous solution $(600 \mu \mathrm{l})$, and was incubated at $4^{\circ} \mathrm{C}$ for 1.5 hours. After centrifugation at $12,000 \times \mathrm{g}$ for 10 minutes at $4^{\circ} \mathrm{C}$, the pellet was washed with $75 \%$ ethanol $(1.4 \mathrm{~mL})$ and then stored in $75 \%$ ethanol $(1 \mathrm{~mL})$ at $-80^{\circ} \mathrm{C}$. The stored RNA was pelleted by centrifugation and resuspended in diethylpyrocarbonate-treated water $(20 \mu \mathrm{l})$, and the concentration was determined by measuring the absorbance at $280 \mathrm{~nm}$. A $5 \mu \mathrm{g}$ portion of the total RNA was used to prepare cDNA using the GeneRacer kit (Invitrogen), according to the manufacturer's instructions. In brief, total RNA was dephosphorylated using calf intestinal alkaline phosphatase, extracted with phenol-chloroform, and precipitated with ethanol. The RNA was decapped using tobacco acid pyrophosphatase, extracted, and precipitated, and then the GeneRacer 5 ' oligo was ligated to the 5 ' ends. Finally, the RNA was subjected to the reverse transcription reaction using a poly-T primer containing the GeneRacer 3 ' oligo sequence, to generate a single-stranded cDNA library with known $5^{\prime}$ and $3^{\prime}$ sequences.

The amino acid sequence of $\mathrm{HsPol} \eta$ was used for a in-house TBLASTN search of a translated A. pompejana expressed sequence tag (EST) database comprised of sequences derived from collaborations with the Joint Genome Institute (Walnut Creek, CA) and Genome Therapeutics (Waltham, MA). A positive hit at the $5^{\prime}$ end of the gene was identified on EST CAGA3172. The $3^{\prime}$ sequence was determined from the prepared A. pompejana GeneRacer cDNA library by $3^{\prime}$ RACE PCR, using a gene specific primer 
(AlviXPVF1 5'GG GAC TGG TCT GTG CTG GCC GTG GAA AT $3^{\prime}$ ) and the GeneRacer $3^{\prime}$ oligo primer, together with the touchdown PCR strategy and KOD polymerase (Novagen). The PCR product was TOPO cloned into the pCR2.1 vector (Invitrogen) and was analyzed by restriction enzyme digestion and sequencing. The full-length ApPol $\eta$ gene was amplified from the cDNA library, using two gene-specific primers, AlviXPVF1 (the above sequence) and AlviXPVR2 (5' GGG ATG ATT CTA CAC TTT GCT GAA AAA TCT ATC CA $3^{\prime}$ ), and KOD polymerase under the standard PCR conditions. The $2.2 \mathrm{~kb}$ product was gel-purified and TOPO cloned into the pCR4 vector (Invitrogen) and was analyzed by restriction enzyme digestion and sequencing. Restriction sites were added to the ends by a subsequent round of PCR and TOPO cloning. The full-length ApPol $\eta$ cDNA was then subcloned into pET21a (Novagen), using the Nde I and Eco RI restriction nucleases and T4 DNA ligase, and was analyzed by restriction enzyme digestion and sequencing.

2.3. Expression and Purification of the ApPoln Protein. Recombinant ApPol $\eta$ gene was expressed in E. coli Rosetta2 (DE3) (Novagen). The cells were grown at $37^{\circ} \mathrm{C}$ to an absorbance at $600 \mathrm{~nm}$ of 0.6 . The cultures were placed in an ice slurry for 20 minutes, and then isopropyl- $\beta$-Dthiogalactopyranoside was added to a final concentration of $0.5 \mathrm{mM}$. After the cultures were incubated at $12^{\circ} \mathrm{C}$ for 40 hours, the cells were collected by centrifugation, rinsed with buffer A containing $10 \mathrm{mM}$ sodium phosphate $(\mathrm{pH}$ 7.4), $10 \%$ glycerol, and $300 \mathrm{mM} \mathrm{NaCl}$, and resuspended in buffer A containing $p$-amidinophenylmethanesulfonyl fluoride hydrochloride and a protease inhibitor cocktail (complete, EDTA free (Roche)). The lysate mixtures were mixed with powdered lysozyme at a final concentration of $2 \mathrm{mg} / \mathrm{mL}$ for 10 minutes on ice, and then were subjected to ultrasonicationn. The lysates were centrifuged, and the supernatants were mixed with Talon resin (Clontech) $(50 \%$ $\mathrm{w} / \mathrm{v}$, equilibrated with lysis buffer containing $10 \mathrm{mM}$ sodium phosphate (pH 7.4), $10 \%$ glycerol, $300 \mathrm{mM} \mathrm{NaCl}$, and $5 \mathrm{mM}$ imidazole). The resin was washed with the same buffer, and the bound proteins were eluted with eluate buffer (lysis buffer containing $300 \mathrm{mM}$ imidazole). The eluate was diluted and applied to a HiTrap Heparin HP column (GE Healthcare) equilibrated with buffer $B(50 \mathrm{mM}$ sodium phosphate (pH 7.4), 1 mM EDTA, $1 \mathrm{mM} \beta$-mercaptoethanol, and $0.01 \%$ Triton X-100) containing $0.1 \mathrm{M} \mathrm{NaCl}$. Elution was performed by a stepwise gradient of $0.2 \mathrm{M}$ to $0.6 \mathrm{M} \mathrm{NaCl}$ in buffer B. The peak fractions containing ApPol $\eta$ eluted at $0.5 \mathrm{M} \mathrm{NaCl}$, and were stored at $-80^{\circ} \mathrm{C}$.

2.4. TLS Reactions. The $5^{\prime}{ }_{-}^{32} \mathrm{P}$-labeled primer-template was prepared by mixing a 16 -mer primer labeled at its $5^{\prime}$ end with each of the 30 -mer templates, at a molar ratio of $1: 1$. Standard reaction mixtures $(10 \mu \mathrm{l})$, containing $40 \mathrm{mM}$ Tris$\mathrm{HCl}$ ( $\mathrm{pH} 8.0$ ), $1 \mathrm{mM} \mathrm{MgCl} 2,100 \mathrm{mM}$ dNTPs, $10 \mathrm{mM}$ DTT, $0.24 \mathrm{mg} / \mathrm{mL}$ BSA, $60 \mathrm{mM} \mathrm{KCl}, 2.5 \%$ glycerol, $40 \mathrm{nM} 5^{\prime}-{ }^{32} \mathrm{P}-$ labeled primer-template, and purified ApPol $\eta$, were incubated at $37^{\circ} \mathrm{C}$. The reaction times and the enzyme amounts are indicated in the figure legends. The reactions were terminated by the addition of stop solution $(8 \mu \mathrm{l})$, containing 95\% formamide, $20 \mathrm{mM}$ EDTA, $0.025 \%$ bromophenol blue, and $0.025 \%$ xylene cyanol. The protein was denatured by boiling, and the products were separated by electrophoresis on a denaturing $16 \%$ polyacrylamide gel. Dried gels were analyzed on a FUJIFILM BAS 1800 bioimage analyzer.

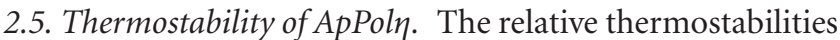
of ApPol $\eta$ and $\mathrm{HsPol} \eta$ were compared by heating each enzyme to temperatures ranging between $37^{\circ} \mathrm{C}$ and $58^{\circ} \mathrm{C}$ for 5 minutes. An aliquot of each enzyme was then used for the standard 20 minutes TLS reaction at $37^{\circ} \mathrm{C}$ to measure the incorporation of a single nucleotide, dCMP, opposite the template $G$ residue (see the TLS reactions described above). The enzyme concentrations used in the reactions were initially determined by making serial dilutions of each enzyme and identifying the concentration necessary to give the same extension level of the labeled primer. These amounts were 1.8 and $5.9 \mathrm{fmol}$ for $\mathrm{HsPol} \eta$ and ApPol $\eta$, respectively. The ability of each enzyme to extend the primer was quantified with MultiGauge software (FUJIFILM), and the specific activity, compared to the activity of each enzyme heated to $37^{\circ} \mathrm{C}$, was calculated. The specific activity was plotted as a function of the temperature to which the enzyme was exposed.

\section{Results}

3.1. Amino Acid Sequence of ApPoln. A cDNA sequence with homology to that of HsPol $\eta$ was cloned from an $A$. pompejana cDNA library by RACE PCR. The open reading frame encoded a predicted product of 745 amino acid residues, with a calculated molecular mass of $83 \mathrm{kDa}$. Alignment of the amino acid sequence against $\mathrm{HsPol} \eta$ revealed $38.1 \%$ identity and $57.6 \%$ similarity overall (identities = $283 / 708(39 \%)$, positives $=414 / 708(58 \%)$, gaps $=68 / 708$ (9\%)). The alignment (Figure 1(a)) also indicated the high conservation within the $\mathrm{N}$-terminal region and the presence of the four structural domains (finger, palm, thumb, and little finger) that are the hallmarks of the Y-family translesion DNA polymerases $[32,33]$. Ubiquitin (Ub)-binding domains [34-36] and a proliferating cell nuclear antigen (PCNA)binding domain $[37,38]$, located in the C-terminal region of Pol $\eta$, were identified in the ApPol $\eta$ amino acid sequence, suggesting that $\mathrm{Ub}$ and/or PCNA regulate this protein.

The Y-family DNA polymerases $\iota(\mathrm{Pol} \iota)$ and $\kappa(\mathrm{Pol} \kappa)$ and the B-family DNA polymerase $\zeta(\mathrm{Pol} \zeta)$ are known to share sequence homology with the Y-family HsPol $\eta$. To analyze the relationship between this $A$. pompejana protein and other translesion DNA polymerases, a phylogenetic tree was produced on the basis of the amino acid sequences of these DNA polymerases, by the unweighted pair group method with arithmetic mean (UPGMA). The tree revealed that this protein was not related to $\mathrm{Pol} \kappa$, Poll, or Pol $\zeta$, but was more closely related to Pol $\eta$ (Figure 1(b)). Therefore, we concluded that this protein is a member of the DNA polymerase $\eta$ 


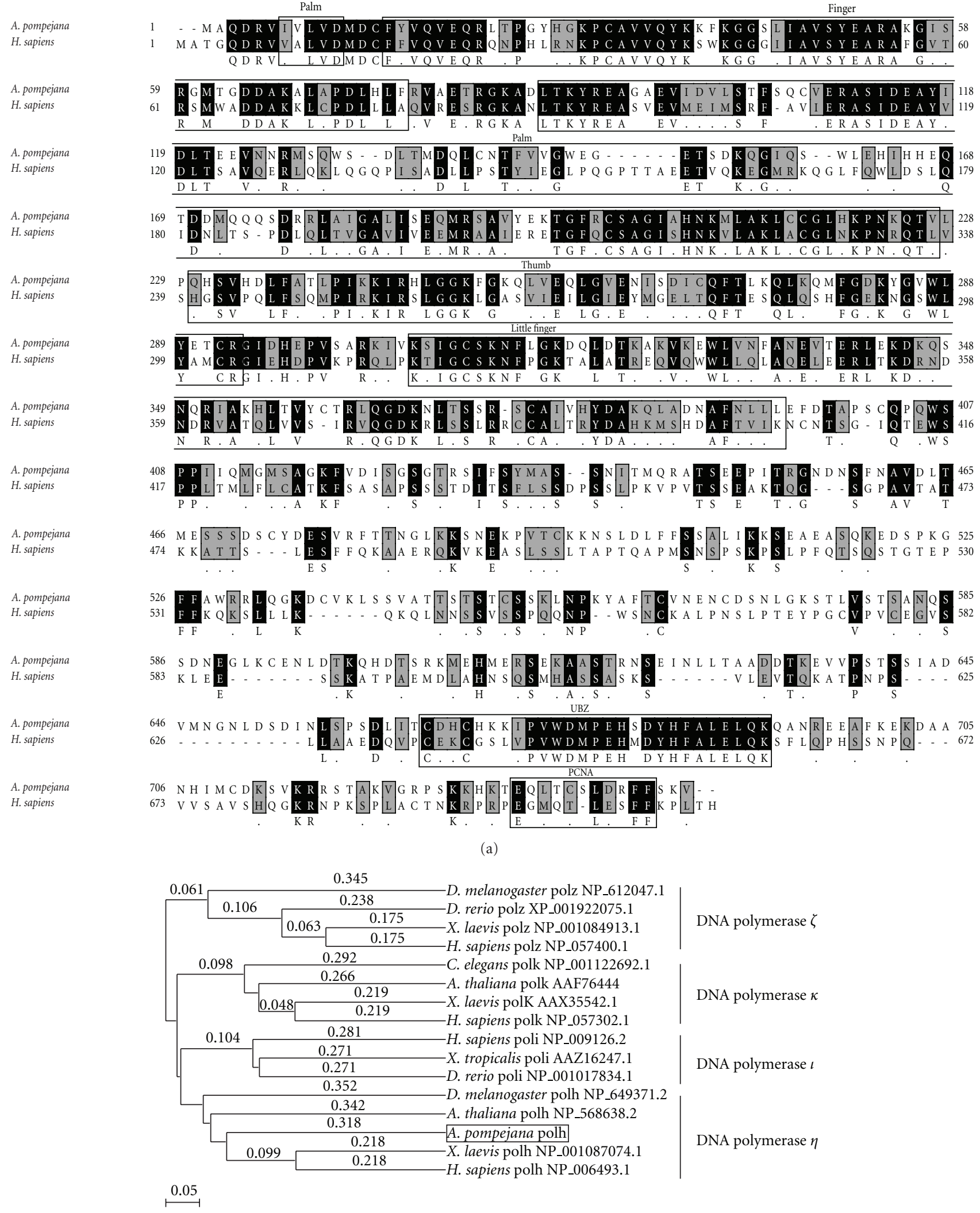

(b)

Figure 1: (a) Alignment of the amino acid sequences of ApPol $\eta$ and HsPol $\eta$ (NP_006493.1). Identical and similar residues between the two enzymes are indicated in black and grey, respectively. (b) Phylogenetic analysis of TLS polymerases. A phylogenetic tree was constructed by the UPGMA method, based on the amino acid sequences of the ApPol $\eta$ and other Y- and B-family DNA polymerases. 


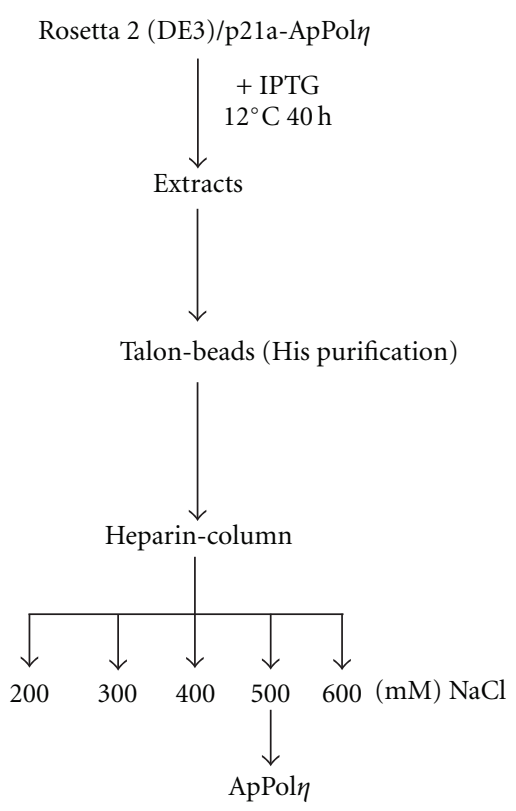

(a)

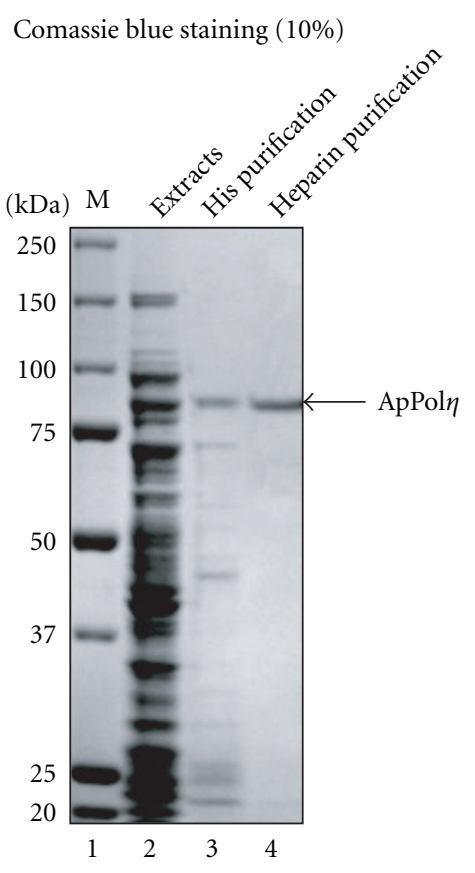

(b)

FIGURE 2: Purification of the recombinant ApPol $\eta$ protein. Aliquots from various steps of the purification were subjected to $10 \%$ SDS-PAGE analysis, and the proteins were visualized by staining with Coomassie Brilliant Blue. ApPol $\eta$ has a molecular mass of $85 \mathrm{kDa}$. Lane 1, markers; lane 2, cell extract; lane 3, Talon eluate; lane 4, HiTrap Heparin HP eluate.

group, and thus referred to the protein as A. pompejana DNA polymerase $\eta$.

3.2. Purification of ApPoln. To examine the biological activities of the protein encoded by the ApPol $\eta$ cDNA, we prepared the recombinant ApPol $\eta$ protein with a C-terminal (His) ${ }_{6}$ tag in E. coli. The extract was first fractionated on Talon beads, and then purified on a Heparin column. The recombinant protein was eluted by a step gradient of $\mathrm{NaCl}$ (Figure 2(a)). As expected from the calculated relative molecular mass, the purified recombinant ApPol $\eta$ bearing the $(\mathrm{His})_{6}$ tag migrated as a single band of approximately $85 \mathrm{kDa}$ in the SDS-PAGE analysis (Figure 2(b)), and exhibited DNA polymerase activity (Figure 3(a)). The recombinant human Y-family polymerases, for example, Pol $\eta$, Pol $l$, and $\mathrm{Pol} \kappa$, are usually prepared from baculovirus-infected insect cells, as reported previously $[13,17,39,40]$. In the present study, the incubation of the cultures at a low temperature after induction enabled the production of full-length ApPol $\eta$ in $E$. coli, as was also reported by Hoffman et al. [41] for Pol $\eta$ from other species. The yield of the purified protein was $15.5 \mu \mathrm{g}$ per liter of the culture.

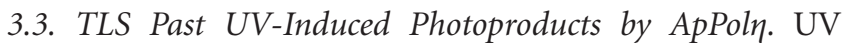
irradiation induces the formation of pyrimidine dimers, namely, CPD and 6-4 pp. The latter is isomerized to Dewar by exposure to UVA/B. HsPol $\eta$ catalyzed efficient and accurate TLS past CPD [13], but not 6-4 pp [13] and Dewar (unpublished results). To examine whether ApPol $\eta$ possessed TLS activity for UV-induced lesions, 30-mer oligonucleotide templates containing a single lesion were hybridized to a $5^{\prime}-{ }^{32} \mathrm{P}$-labeled 16-mer oligonucleotide primer, and these duplexes were employed for the TLS reactions (Figure 3 ). Klenow fragment (KF) inserted one nucleotide opposite $\mathrm{CPD}$, but did not elongate the primer (Figure 3(b), lane 1 ), whereas ApPol $\eta$ could efficiently elongate the primer up to the end of the 30-mer, in an enzyme concentrationdependent manner (Figure 3(b), lanes 3-7). Similar experiments were performed with other UV-induced lesions, 6$4 \mathrm{pp}$ and Dewar. ApPol $\eta$ could insert one nucleotide opposite these lesions, but elongation of the primers was not observed (Figures 3(c) and 3(d)), in a manner similar to $\mathrm{HsPol} \eta$ $[13,42]$.

To examine the preference for nucleotide incorporation opposite the lesion by ApPol $\eta$, the polymerization reactions were performed in the presence of only a single deoxyribonucleoside triphosphate (Figure 4). Although HsPol $\eta$ replicates undamaged DNA with low fidelity $[43,44]$, it can accurately incorporate dATP opposite the TT sequence of CPD [13]. On the undamaged template, ApPol $\eta$ preferred to incorporate dATP correctly, and dGTP was incorporated less frequently (Figure 4(a)), indicating that ApPol $\eta$, like HsPol $\eta$, replicates undamaged DNA with low fidelity. When the template contained CPD, ApPol $\eta$ incorporated dATP exclusively (Figure 4(b), lane 4), indicating that ApPol $\eta$, like HsPol $\eta$, can accurately perform TLS past CPD. For both 6$4 \mathrm{pp}$ and Dewar, primers that were elongated with dAMP and dGMP by ApPol $\eta$ were detected, although the elongation efficiency was very low (Figures 4(c) and 4(d)). While we are able to test these activities biochemically, establishing the 

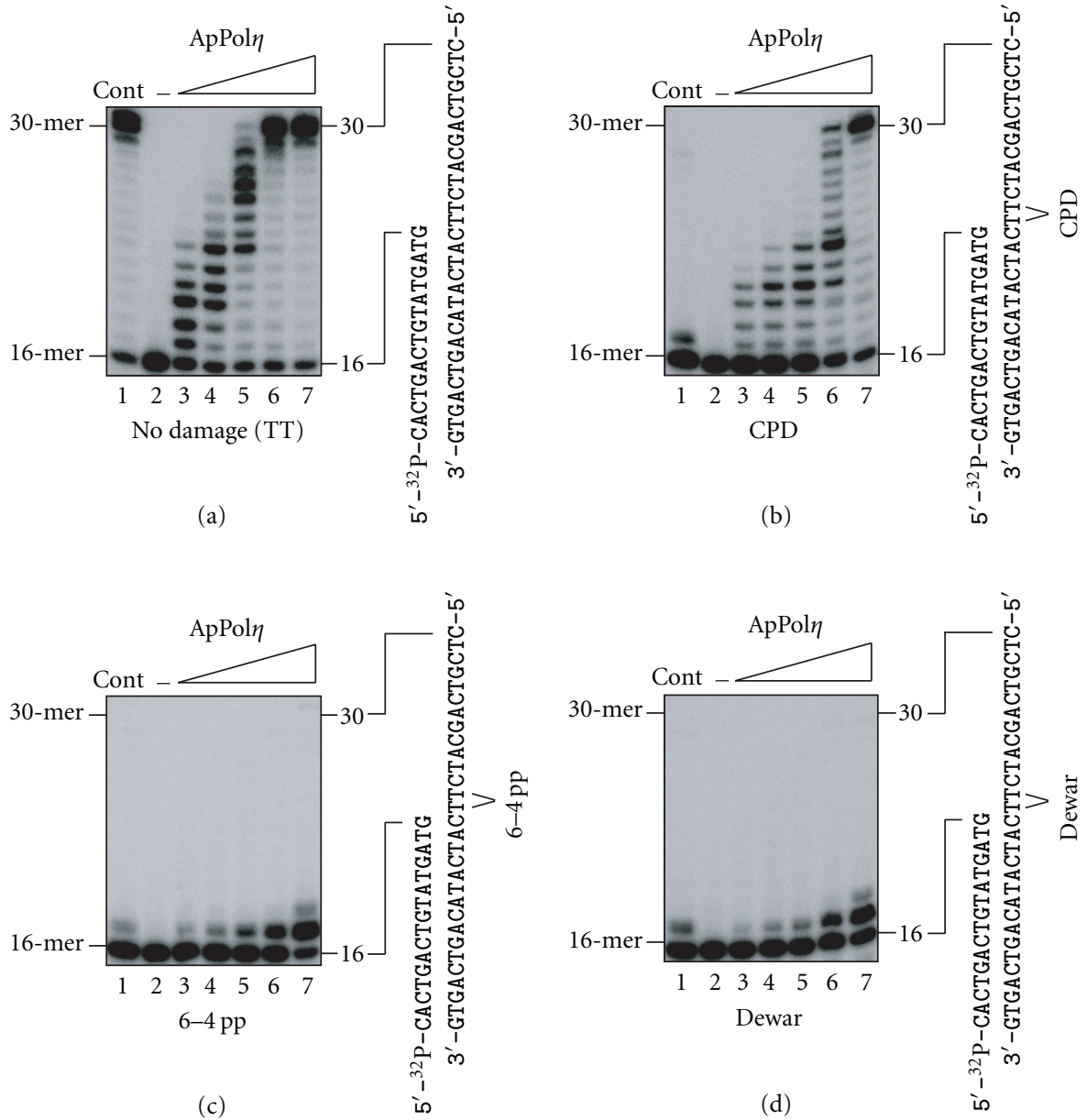

Figure 3: TLS by ApPol $\eta$ past CPD, 6-4 pp, and Dewar. Increasing amounts of ApPol $\eta(12,24,59,118$, and 588 fmol in lanes 3-7, resp.) were incubated with $40 \mathrm{nM}$ of the primer-templates indicated beside each panel. The templates contained undamaged TT (a), CPD (b), 6-4 pp (c), and Dewar (d). The samples for lanes 1 and 2 contained $0.1 \mathrm{U} \mathrm{KF}$ and no enzyme, respectively. The reactions were incubated at $37^{\circ} \mathrm{C}$ for 20 minutes, and then were subjected to $15 \%$ polyacrylamide/7.5 M urea gel electrophoresis. The autoradiograms of the gels are shown.

biological roles of ApPol $\eta$ would require additional assays such as genetic complementation, however these results were also similar to those obtained for $\mathrm{HsPol} \eta$.

3.4. TLS Past Oxidative Lesions by ApPoln. Since A. pompejana inhabits deep sea thermal vent regions that are in excess of $1.5 \mathrm{~km}$ under the ocean surface where UV-rays from the sun do not penetrate $[45,46]$, we thought that CPD containing DNA may not be a major template for ApPol $\eta$. Other candidates were assumed to be oxidative lesions, because the high temperature and the solutes at the hydrothermal vent sites might induce oxidative stress. $\mathrm{Tg}$ is one of the major DNA lesions produced by ROS, and two isomeric forms, $5 R-\mathrm{Tg}$ and $5 S-\mathrm{Tg}$, are produced in DNA. Tg often blocks DNA replication by replicative DNA polymerases [40], but rarely induces mutation [41]. However, $\mathrm{HsPol} \eta$ can catalyze efficient and accurate TLS past each Tg isomer [17].

Using the 30-mer oligonucleotides containing a single lesion at the 17th nucleotide from its $3^{\prime}$ end as templates, we examined the ability of ApPol $\eta$ to replicate DNA past
$5 R-\mathrm{Tg}$ and $5 S$-Tg. At both lesions, the replicative T7 DNA polymerase was blocked completely (Figures 5(a) and 5(b), lane 1), but ApPol $\eta$ efficiently catalyzed the replication reaction (Figures 5(a) and 5(b), lanes 3-7). To examine the preference of nucleotide incorporation opposite each $\mathrm{Tg}$ isomer, the polymerization reactions were tested in the presence of only a single deoxyribonucleoside triphosphate (Figures 6(a) and 6(b)). ApPol $\eta$ preferred to incorporate dATP (Figures 6(a) and 6(b), lane 4). Although dGTP was incorporated in the absence of the other nucleotides (lane 6), this product, which exhibited slightly slower migration in the PAGE analysis, was not detected when the four nucleotides were added (lane 3). These results indicated that ApPol $\eta$ had the ability to catalyze TLS accurately past both $5 R$-Tg and $5 S$-Tg.

Another major oxidative DNA lesion induced by ROS is 8 -oxoG, which is an important promutagen in vivo and in vitro [1]. Similar experiments were performed with a template containing 8-oxoG, instead of Tg. No insertion of any nucleotide opposite the lesion by T7 DNA polymerase was observed (Figure 5(d), lane 1), whereas ApPol $\eta$ could 

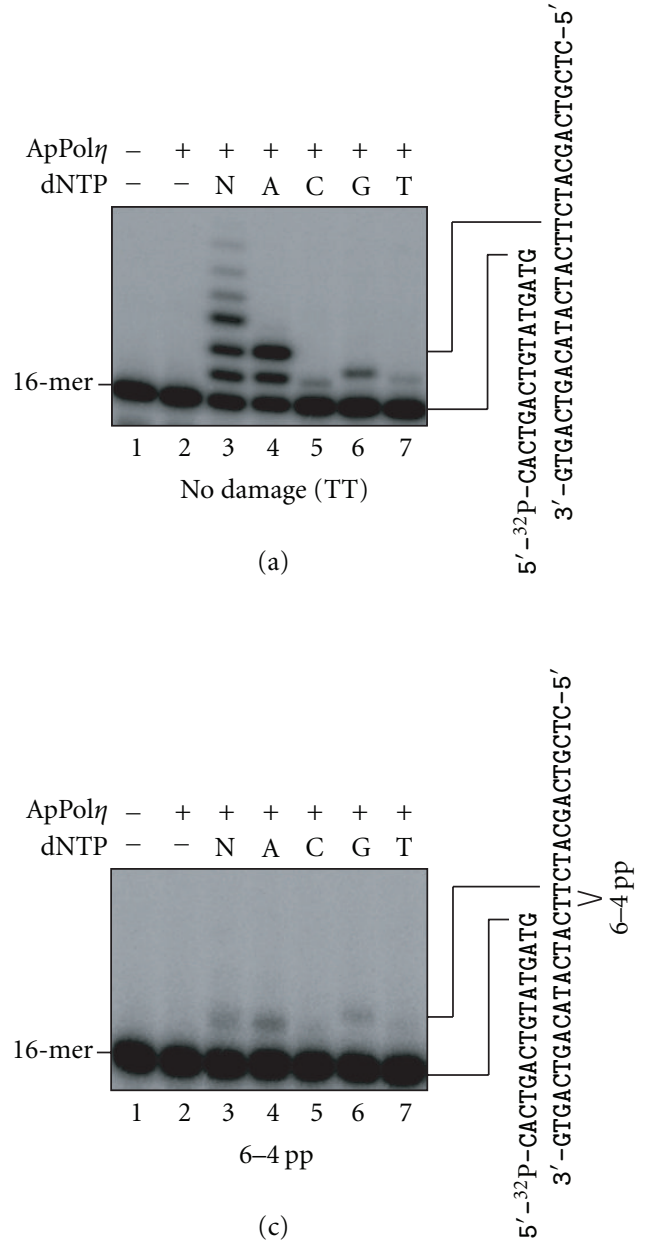
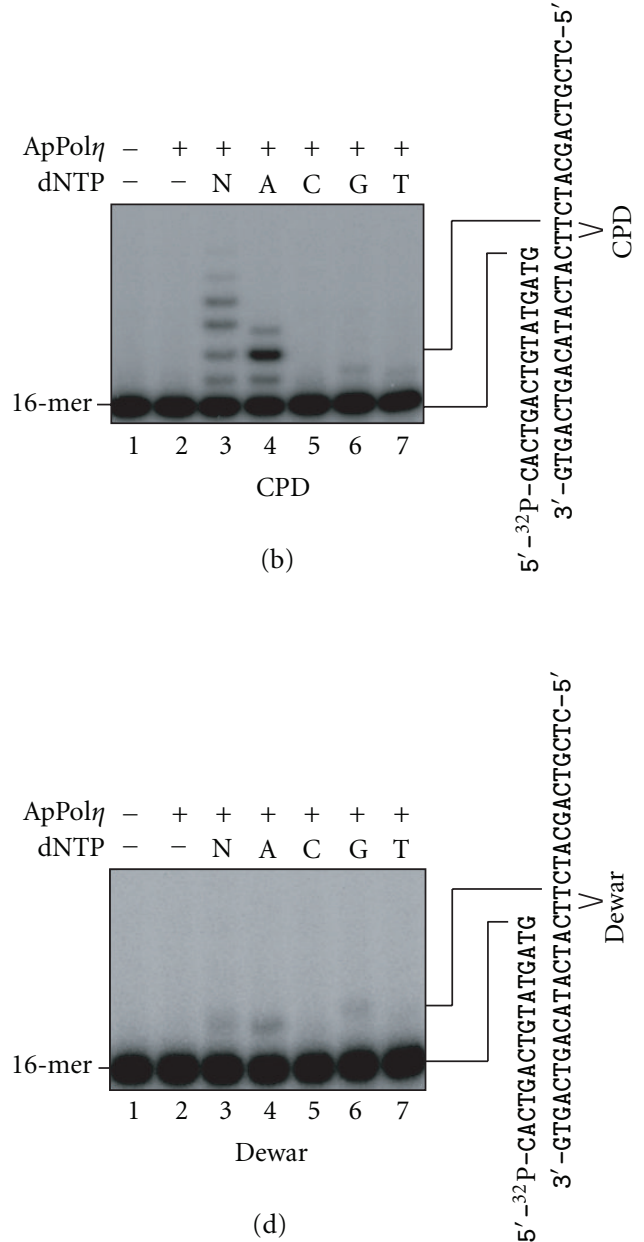

FIgURE 4: Selectivity of nucleotide incorporation by ApPol $\eta$ opposite undamaged TT (a), CPD (b), 6-4 pp (c), and Dewar (d). ApPol $\eta$ (12 fmol in lanes 2-7) was incubated with each primer-template in the presence of the four dNTPs (lane 3), the indicated dNTP (lanes 4-7), or the absence of dNTP (lane 2). Lane 1 contained no enzyme. The reactions were incubated at $37^{\circ} \mathrm{C}$ for 5 minutes, and then were subjected to $15 \%$ polyacrylamide/7.5 M urea gel electrophoresis. The autoradiograms of the gels are shown.

bypass 8-oxoG efficiently (Figure 5(d), lanes 3-7). For the nucleotide preference, ApPol $\eta$ preferred to incorporate the correct dCTP opposite the undamaged template G (Figure 6(c)), whereas it mainly incorporated the incorrect dATP opposite 8-oxoG (Figure 6(d)). Thus, this enzyme replicates DNA containing 8-oxoG efficiently but incorrectly, leading to frequent $\mathrm{G} \cdot \mathrm{C}$ to $\mathrm{T} \cdot \mathrm{A}$ transversions. In addition, we investigated whether ApPol $\eta$ has TLS activity on a template containing the AP site analog. However, like the other Yfamily DNA polymerases, this enzyme was unable to catalyze TLS past this lesion (data not shown).

3.5. In Vitro Stability of ApPoln. As A. pompejana colonizes the walls of actively venting high-temperature chimneys $[23,45,46]$, we hypothesized that its enzymes may be more thermostable than those found in mesophilic organisms, as shown for other TLS polymerases derived from single cellular hyperthermophilic organisms such as Sulfolobus solfataricus DNA polymerase 4 (Dpo4) [47, 48]. To test this possibility, we compared the activity of ApPol $\eta$ along with that of HsPol $\eta$ after heating both enzymes to various temperatures for 5 minutes. After this treatment, we tested the ability of both enzymes to incorporate a single dCMP opposite a template G. As shown in Figure 7, ApPol $\eta$ retained the activity even after it was heated to $49^{\circ} \mathrm{C}$. In contrast, the activity of $\mathrm{HsPol} \eta$ diminished rapidly after heating to temperatures higher than $43^{\circ} \mathrm{C}$. Therefore, ApPol $\eta$ is relatively more thermostable than $\mathrm{HsPol} \eta$.

3.6. Stability of ApPoln in Organic Solvents. As a further test of ApPol $\eta$ stability, we tested the ability of ApPol $\eta$ to incorporate dCMP opposite a template $\mathrm{G}$ in the presence of various organic solvents. In these assays, dimethyl sulfoxide (DMSO), ethanol, and isopropanol (IPA) were used at concentrations of $20 \%(\mathrm{v} / \mathrm{v})$. Similar experiments were performed in a study on TLS past a benzo[a]pyrene adduct by another thermostable Y-family DNA polymerase, archaeal Dpo4, although the organic solvents were added to stabilize the benzo $[a]$ pyrene moiety in the major groove, rather than to test the protein stability [45]. As shown in Figure 8(a), 

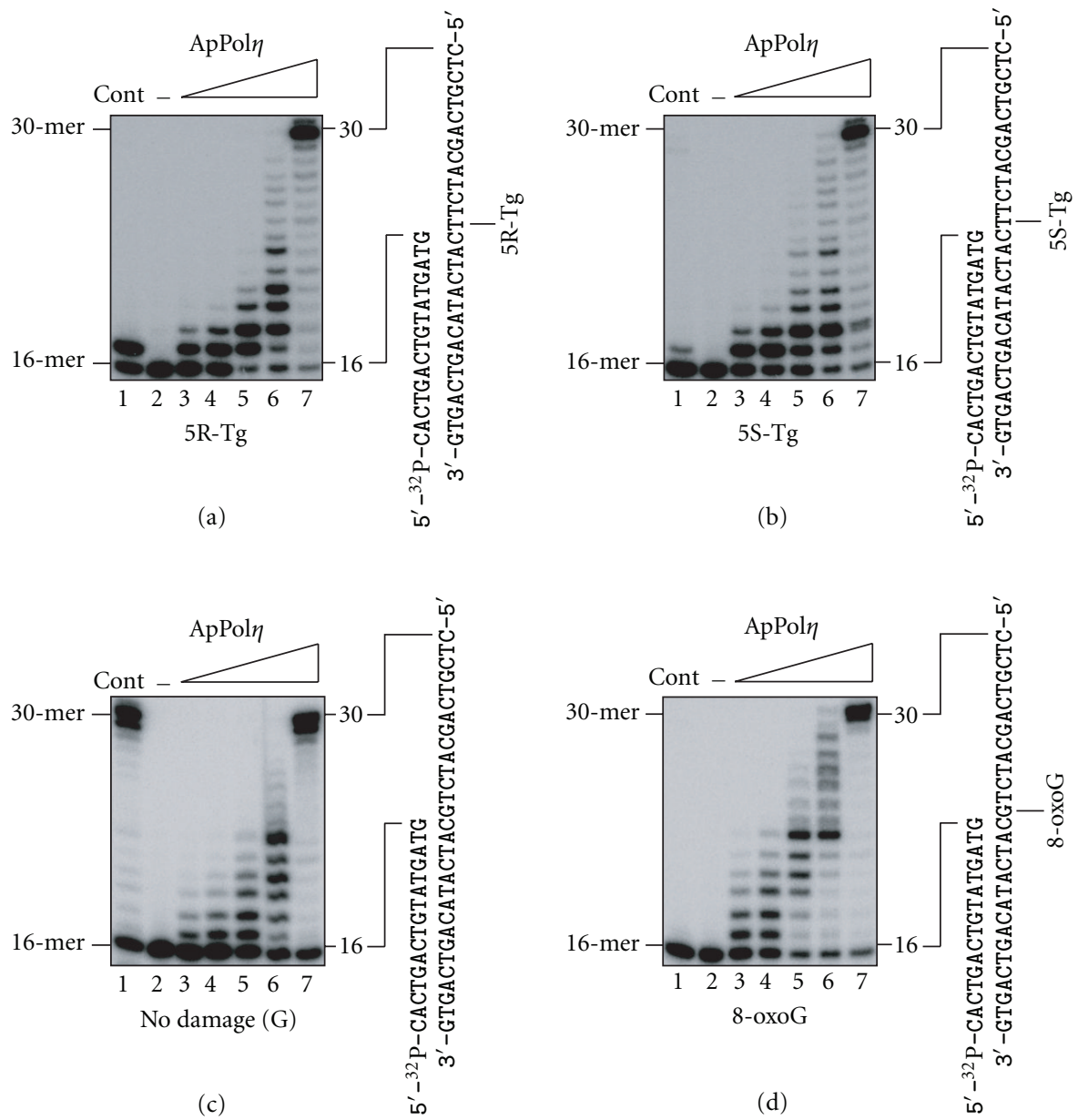

Figure 5: TLS by ApPol $\eta$ past 5R-Tg, 5S-Tg, and 8-oxoG. Increasing amounts of ApPol $\eta(12,24,59,118,588$ fmol in lanes 3-7, resp.) were incubated with $40 \mathrm{nM}$ of the primer-templates indicated beside each panel. The templates contained $5 R-\mathrm{Tg}$ (a), $5 S$ - $\mathrm{Tg}$ (b), undamaged $\mathrm{G}$ (c), and 8-oxoG (d). The samples for lanes 1 and 2 contained $0.1 \mathrm{U}$ T7 DNA polymerase and no enzyme, respectively. The reactions were incubated at $37^{\circ} \mathrm{C}$ for 20 minutes, and then were subjected to $15 \%$ polyacrylamide/7.5 M urea gel electrophoresis. The autoradiograms of the gels are shown.

ApPol $\eta$ exhibited higher activity than $\mathrm{HsPol} \eta$ in the presence of all of the solvents used in this study, although IPA greatly reduced the enzyme activity. In the presence of DMSO, ApPol $\eta$ retained the full activity, even when the reaction mixture contained this solvent at a concentration of $20 \%$ (Figure 8(b)). These results support our conclusion that the full-length ApPol $\eta$ protein is more stable than its human homolog.

\section{Discussion}

4.1. CPD and $T g$ in TLS by ApPoln. In this study, we cloned the cDNA encoding the novel thermostable DNA polymerase $\eta$ from $A$. pompejana, which colonizes deepsea hydrothermal vents. This enzyme was produced in $E$. coli, and was purified as a full-length recombinant protein $(85 \mathrm{kDa})$ bearing a (His) ${ }_{6}$ tag. The purified ApPol $\eta$ protein displayed DNA polymerase activity. This enzyme catalyzed TLS past CPD, $5 R-T g$, $5 S-T g$, and 8-oxoG, but not past 6$4 \mathrm{pp}$, Dewar, or the AP site analog, in a similar manner to
TABle 1: Comparison of nucleotide incorporation into lesioncontaining template-primers between $\mathrm{HsPol} \eta$ and ApPol $\eta$.

\begin{tabular}{|c|c|c|}
\hline DNA lesion & HsPol $\eta$ & ApPol $\eta$ \\
\hline CPD & AA [7-10] & $\mathrm{AA}$ \\
\hline $6-4 \mathrm{pp}$ & $-^{\mathrm{a}}[9,10]$ & $-^{\mathrm{a}}$ \\
\hline Dewar & —a,b & $-^{\mathrm{a}}$ \\
\hline $5 R-\mathrm{Tg}$ & A [15] & A \\
\hline $5 S-\mathrm{Tg}$ & A [15] & $\mathrm{A}$ \\
\hline 8-oxoG & $\mathrm{C} / \mathrm{A}[16,17]$ & $\mathrm{C} / \mathrm{A}$ \\
\hline AP site analog & $-^{\mathrm{a}}[10,17]$ & $-^{\mathrm{a}}$ \\
\hline
\end{tabular}

HsPol $\eta$ (Table 1). We also demonstrated that ApPol $\eta$ was more stable than HsPol $\eta$.

Despite the fact that $A$. pompejana inhabits the deep sea, where UV-rays do not penetrate, the UV-induced CPD was found to be an excellent template for ApPol $\eta$. Considering 

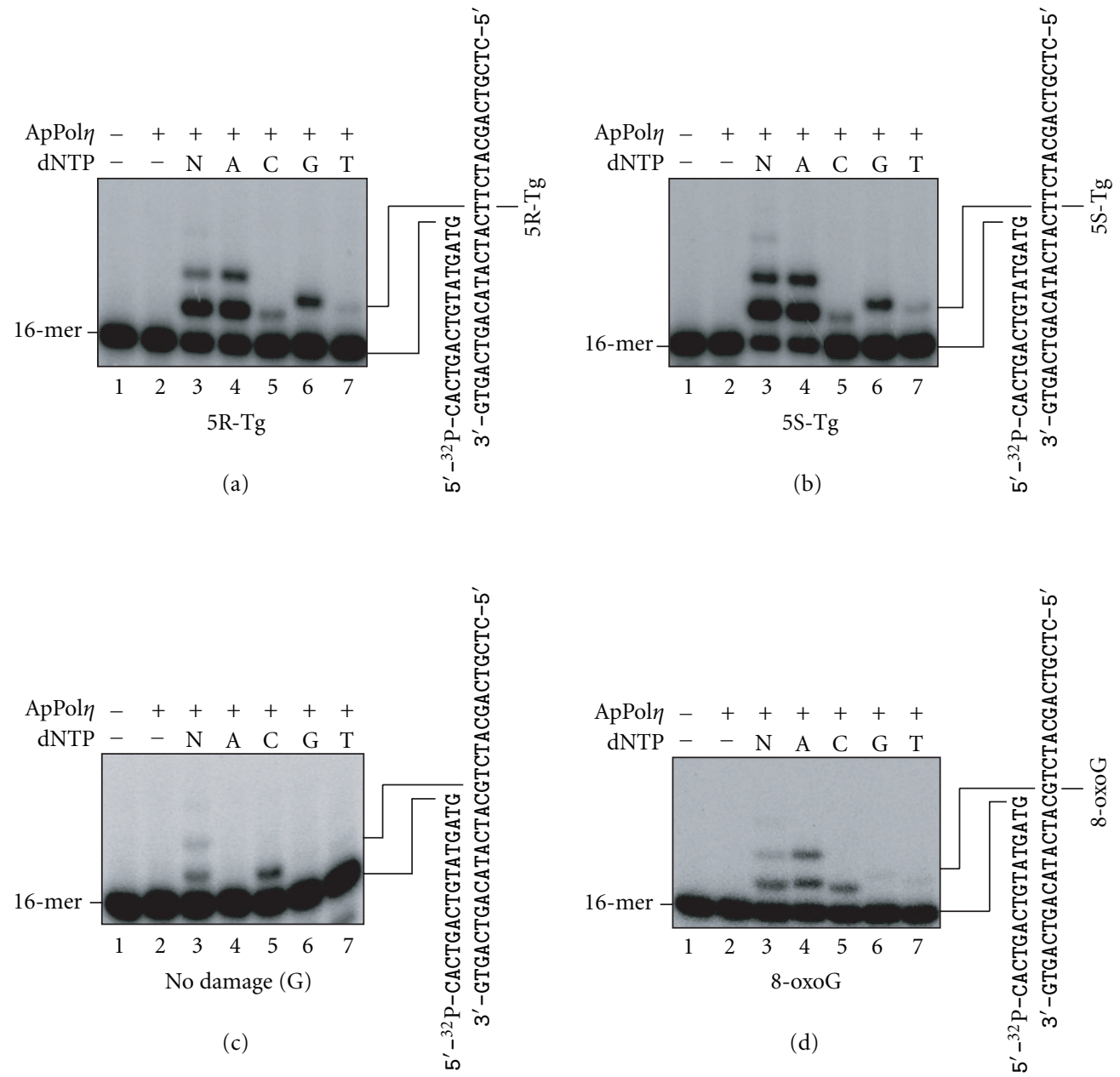

FIGURE 6: Selectivity of nucleotide incorporation by ApPol $\eta$ opposite 5R-Tg (a), 5S-Tg (b), undamaged G (c), and 8-oxoG (d). ApPol $\eta$ (12 fmol in lanes 2-7) was incubated with each primer-template in the presence of the four dNTPs (lane 3), the indicated dNTP (lanes 4-7), or the absence of dNTP (lane 2). Lane 1 contained no enzyme. The reactions were incubated at $37^{\circ} \mathrm{C}$ for 5 minutes, and then were subjected to $15 \%$ polyacrylamide/7.5 M urea gel electrophoresis. The autoradiograms of the gels are shown.

that a genetic defect in the HsPol $\eta$ gene results in the XP-V syndrome, and that XP-V patients are sensitive to sunlight and highly prone to cancer development, the critical role of $\mathrm{HsPol} \eta$ is thought to be error-free TLS across CPD in human cells. As A. pompejana's environment is significantly less subject to UV radiation produced by the sun, we speculate that the inclusion of the TLS polymerase system within the organism may arise from specific environmental adaptations. Evidence for photosynthetic events at hydrothermal vent sites has been noted [49], where energy for the reactions may arise from vent activity. Moreover, the vent area is sporadically subject to periods of intense volcanic and geothermal activity that may cause production of bulky DNA lesions within these organisms. The presence of ApPol $\eta$ may also play a role in protecting developing embryos, as embryos pass through a period of developmental arrest when passing from one colony site to another before renewed growth [50]. In these cases, they may experience periods of geothermal light during passage and during their development at their new colonization site. Thus, these Pol $\eta$ proteins may protect the embryo until it becomes more self-motile and can build its housing tube.

Here, we also showed that this polymerase catalyzes efficient and accurate TLS past both $5 R$ - Tg and $5 S$ - Tg, which are generated by ROS. Since Tg can block DNA replication by replicative DNA polymerases and also induces cell death, the critical role of ApPol $\eta$ might be error-free TLS across Tg in A. pompejana cells.

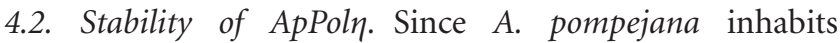
hydrothermal vent sites at temperatures that often measure within the representative classifications for thermophilic $\left(40-60^{\circ} \mathrm{C}\right)$ and hyperthermophilic organisms $\left(60^{\circ} \mathrm{C}\right.$ and higher), we expected that ApPol $\eta$ would be thermostable. In agreement with these expectations, we found that ApPol $\eta$ was more thermostable than $\mathrm{HsPol} \eta$ (Figure 7), but less stable than an archaeal DinB-like polymerase from the hyperthermophile $S$. solfataricus $\mathrm{P} 2[47,51]$ which lives at higher temperatures $\left(>75^{\circ} \mathrm{C}\right)$ than $A$. pompejana. Posttranslational modification of proteins is sometimes important for 


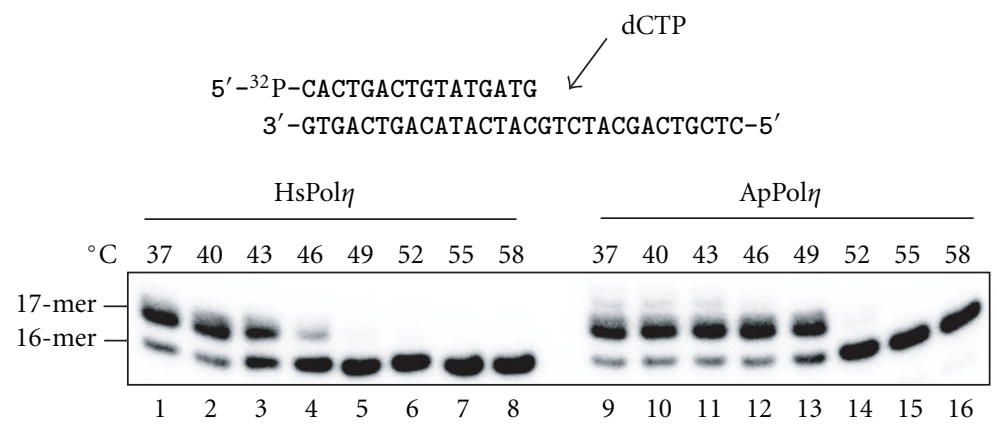

(a)

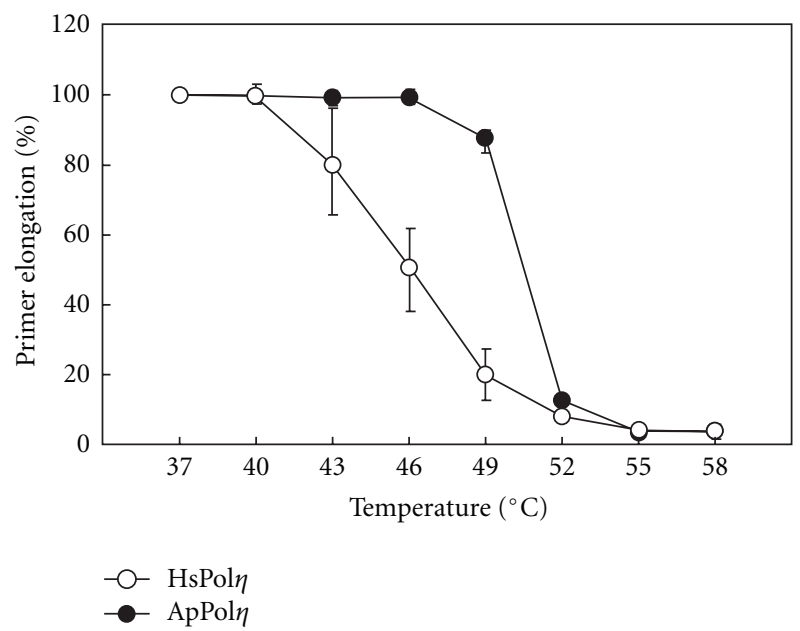

(b)

Figure 7: Thermostability of ApPol $\eta$. (a) Aliquots of ApPol $\eta$ (closed circles) and HsPol $\eta$ (open circles) were heated to the indicated temperature for 5 minutes. The effect of this treatment on the polymerase activity was subsequently determined by analyzing the respective enzyme's ability to extend a radiolabeled primer by incorporating dCMP opposite the template G. Replication assays were performed at $37^{\circ} \mathrm{C}$ for 20 minutes. (b) The ability of each enzyme to extend the primer was quantified, and the specific activity compared to that of each enzyme heated at $37^{\circ} \mathrm{C}$ was calculated and subsequently plotted as a function of the temperature to which the enzyme was initially exposed.

their structure and function. Since the ApPol $\eta$ used in this study was produced in E. coli, the measured thermostability was that without eukaryotic post-translational modifications. We expected that this enzyme may be modified in insect cells, which are more closely related to A. pompejana cells than to $E$. coli cells, and thus might gain higher thermostability. Therefore, we prepared ApPol $\eta$ in Sf9 insect cells using the baculovirus expression system. The ApPol $\eta$ protein produced in Sf9 cells could catalyze DNA synthesis at $37^{\circ} \mathrm{C}$, but lacked translesion activity after it was heated to $55^{\circ} \mathrm{C}$ (data not shown).

There might be several reasons why ApPol $\eta$ is not even more thermostable. (1) It has been reported that Pol $\eta$ functions in a replication complex during TLS [37, 38, 52]. Thus, it is possible that ApPol $\eta$ becomes more heat resistant with the help of other thermostable replication proteins in A. pompejana cells. In fact, ApPol $\eta$ has a PCNA binding motif (Figure 1(a)), indicating that ApPol $\eta$ may exist in a replication complex with PCNA. (2) Y-family DNA polymerases replicate undamaged DNA in an error-prone manner [34-36, 38]. Hence, to maintain genetic integrity, it might not be favorable for cells to have an extremely stable mutator polymerase. The present study is the starting point for the elucidation of the temperature preference of each A. pompejana enzyme and its biological significance, which will further our understanding of the ecology of this unique living organism.

ApPol $\eta$ could be useful for in vitro studies as a new paradigm system to understand TLS mechanisms and also could be a starting material for the development of a more stable eukaryotic-like TLS polymerase by directed evolution. Such an enzyme will enable us to amplify heavily damaged DNA, such as ancient DNA, by PCR-like methods.

\section{Conclusions}

In this study, we cloned an A. pompejana gene with homology to the HsPol $\eta$ gene. The primary structure of the protein indicated the conservation of the PCNA binding domain and the ubiquitin-binding zinc finger motif. The encoded fulllength recombinant protein, ApPol $\eta$, was readily produced in Escherichia coli and purified. We demonstrated that ApPol $\eta$ could bypass CPD, 8-oxoG, 5R-Tg, and $5 S-\mathrm{Tg}$, but not 

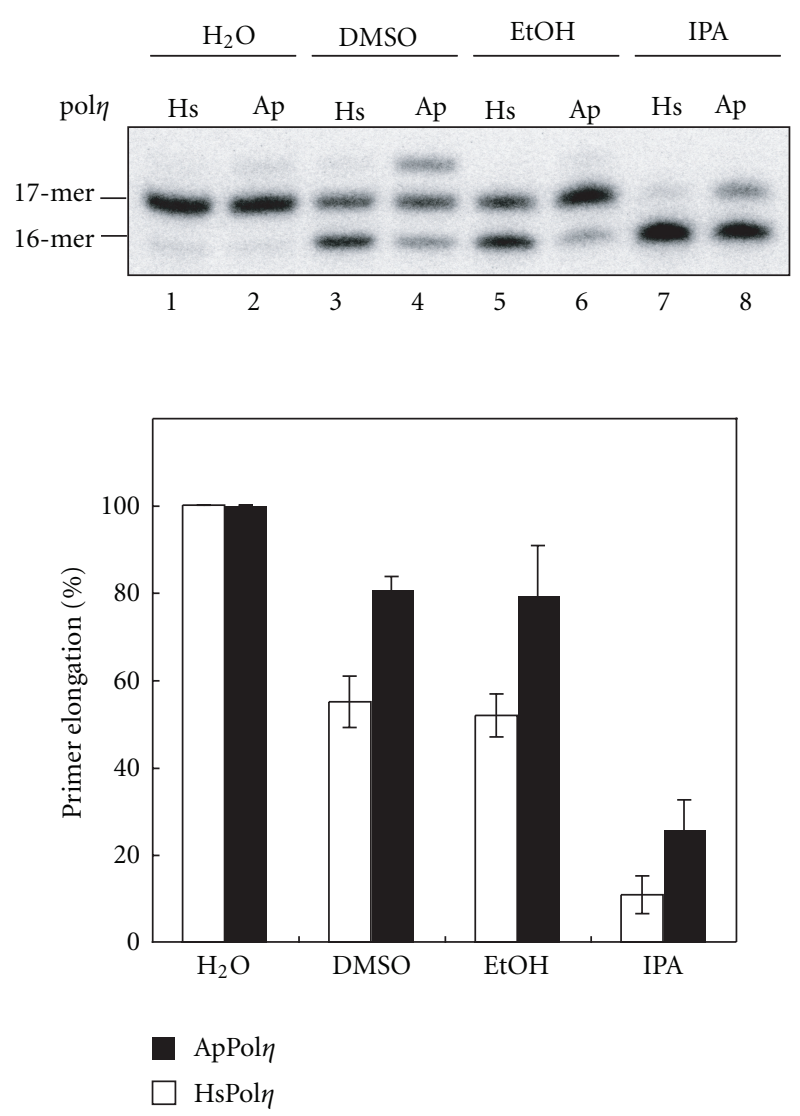

(a)
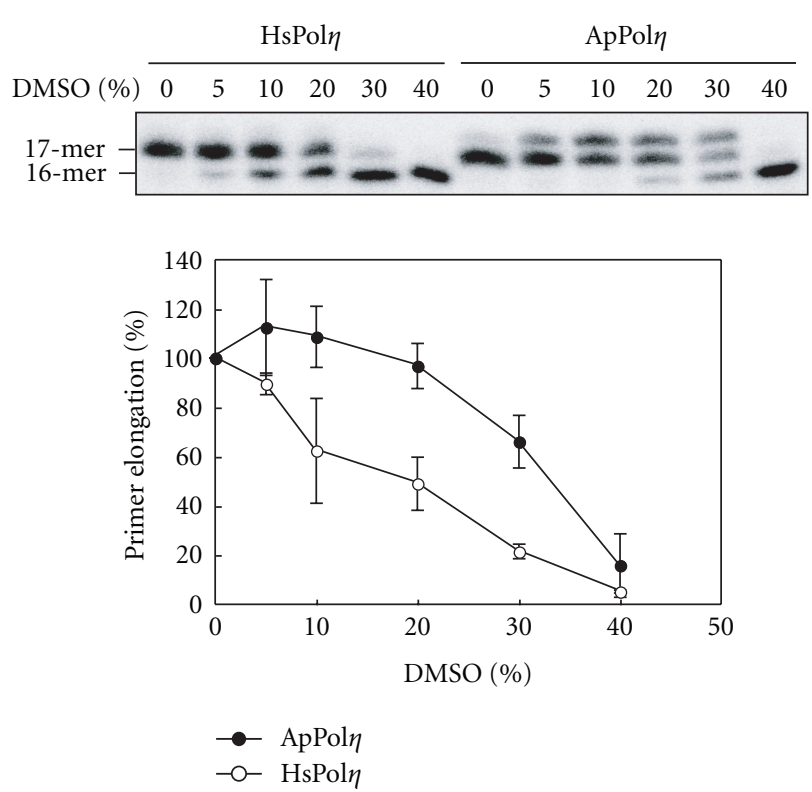

(b)

FIgURe 8: Activity of ApPol $\eta$ in organic solvent-containing solutions. (a) Incorporation of dCMP in the presence of DMSO, ethanol, and IPA at a concentration of $20 \%(\mathrm{v} / \mathrm{v})$ was analyzed, using the primer-template shown in Figure 7. Replication assays were performed at $30^{\circ} \mathrm{C}$ for 10 minutes. (b) The same assays were performed with various concentrations of DMSO.
6-4 pp, Dewar, or any AP site analog revealing a similar spectrum of activities to those of the human homolog. ApPol $\eta$ 's properties of higher stability with human-like activities offer advantages over other known eukaryotic TLS polymerases for future basic and practical applications.

\section{Acknowledgments}

The authors thank S. C. Cary and B. R. Chapados for technical support. They thank the R/V Atlantis and DSV Alvin crews in aiding A. pompejana sample collection and the Department of Energy (DOE) Joint Genome Institute for partial EST sequencing for this work. This work was supported by Human Frontier Science Program (J. A. Tainer, F. Hanaoka, S. Iwai), by the 3rd Annual Incyte Discovery Award (D. S. Shin, J. A. Tainer), by the US National Institutes of Health Grants GM46312 (JAT), and by DOE program Integrated Diffraction Analysis Technologies (J. A. Tainer) and DOE Community Sequence Program award (D. S. Shin, J. A. Tainer). D. S. Shin and K. Hitomi were supported in part by Skaggs Institute for Chemical Biology, and D. S. Shin was further supported in part by a Ruth L. Kirschstein NSRA Fellowship. Bulky lesion repair in the Tainer lab is support by NIH grant R01 CA112093. J. O. Fuss and Q. J. Cheng were supported in part by the US National Cancer Institute Grant CA112093 and the US Department of Energy Molecular Assemblies: Genes and Genomes Integrated Efficiently Project (DE-FG0207ER64326), plus the NRSA Fellowship 1F32CA108393 to J. O. Fuss.

\section{References}

[1] E. C. Friedberg, G. C. Walker, W. Siede, R. D. Wood, R. A. Schultz, and T. Ellenberger, DNA Repair and Mutagenesis, American Society for Microbiology, Washington, DC, USA, 2nd edition, 2005.

[2] J. H. J. Hoeijmakers, "Genome maintenance mechanisms for preventing cancer," Nature, vol. 411, no. 6835, pp. 366-374, 2001.

[3] T. Lindahl and R. D. Wood, "Quality control by DNA repair," Science, vol. 286, no. 5446, pp. 1897-1905, 1999.

[4] E. C. Friedberg, A. R. Lehmann, and R. P. P. Fuchs, “Trading places: how do DNA polymerases switch during translesion DNA synthesis?" Molecular Cell, vol. 18, no. 5, pp. 499-505, 2005.

[5] A. R. Lehmann, A. Niimi, T. Ogi et al., "Translesion synthesis: Y-family polymerases and the polymerase switch," DNA Repair, vol. 6, no. 7, pp. 891-899, 2007.

[6] H. Ohmori, E. C. Friedberg, R. P. P. Fuchs et al., "The Y-family of DNA polymerases," Molecular Cell, vol. 8, no. 1, pp. 7-8, 2001.

[7] A. M. Cordonnier and R. P. P. Fuchs, "Replication of damaged DNA: molecular defect in Xeroderma pigmentosum variant cells," Mutation Research, vol. 435, no. 2, pp. 111-119, 1999.

[8] A. R. Lehmann, S. Kirk Bell, and C. F. Arlett, "Xeroderma pigmentosum cells with normal levels of excision repair have a defect in DNA synthesis after UV irradiation," Proceedings of the National Academy of Sciences of the United States of America, vol. 72, no. 1, pp. 219-223, 1975. 
[9] R. E. Johnson, C. M. Kondratick, S. Prakash, and L. Prakash, "hRAD30 mutations in the variant form of xeroderma pigmentosum," Science, vol. 285, no. 5425, pp. 263-265, 1999.

[10] C. Masutani, R. Kusumoto, A. Yamada et al., "The XPV (xeroderma pigmentosum variant) gene encodes human DNA polymerase $\eta$," Nature, vol. 399, no. 6737, pp. 700-704, 1999.

[11] J. T. Reardon, A. F. Nichols, S. Keeney et al., "Comparative analysis of binding of human damaged DNA-binding protein (XPE) and Escherichia coli damage recognition protein (UvrA) to the major ultraviolet photoproducts: $\mathrm{T}[\mathrm{c}, \mathrm{s}] \mathrm{T}$, $\mathrm{T}[\mathrm{t}, \mathrm{s}] \mathrm{T}, \mathrm{T}[6-4] \mathrm{T}$, and T[Dewar] T," Journal of Biological Chemistry, vol. 268, no. 28, pp. 21301-21308, 1993.

[12] A. van Hoffen, J. Venema, R. Meschini, A. A. van Zeeland, and L. H. F. Mullenders, "Tvanscription-coupled repair removes both cyclobutane pyrimidine dimers and 6-4 photoproducts with equal efficiency and in a sequential way from transcribed DNA in xeroderma pigmentosum group C fibroblasts," EMBO Journal, vol. 14, no. 2, pp. 360-367, 1995.

[13] C. Masutani, R. Kusumoto, S. Iwai, and F. Hanaoka, "Mechanisms of accurate translesion synthesis by human DNA polymerase $\eta$," EMBO Journal, vol. 19, no. 12, pp. 3100-3109, 2000.

[14] M. B. de Moura, B. L. F. Schamber-Reis, D. G. P. Silva et al., "Cloning and characterization of DNA polymerase $\eta$ from Trypanosoma cruzi: roles for translesion bypass of oxidative damage," Environmental and Molecular Mutagenesis, vol. 50, no. 5, pp. 375-386, 2009.

[15] L. Haracska, M. T. Washington, S. Prakash, and L. Prakash, "Inefficient bypass of an abasic site by DNA polymerase $\eta$," Journal of Biological Chemistry, vol. 276, no. 9, pp. 6861-6866, 2001.

[16] L. Haracska, S.-L. Yu, R. E. Johnson, L. Prakash, and S. Prakash, "Efficient and accurate replication in the presence of 7,8-dihydro-8-oxoguanine by DNA polymerase $\eta$," Nature Genetics, vol. 25, no. 4, pp. 458-461, 2000.

[17] R. Kusumoto, C. Masutani, S. Iwai, and F. Hanaoka, "Translesion synthesis by human DNA polymerase $\eta$ across thymine glycol lesions," Biochemistry, vol. 41, no. 19, pp. 6090-6099, 2002.

[18] S. D. Mcculloch, R. J. Kokoska, P. Garg, P. M. Burgers, and T. A. Kunkel, "The efficiency and fidelity of 8-oxo-guanine bypass by DNA polymerases $\delta$ and $\eta$," Nucleic Acids Research, vol. 37, no. 9, pp. 2830-2840, 2009.

[19] Y. Zhang, F. Yuan, X. Wu et al., "Error-prone lesion bypass by human DNA polymerase $\eta$," Nucleic Acids Research, vol. 28, no. 23, pp. 4717-4724, 2000.

[20] M. J. Mcllwraith, A. Vaisman, Y. Liu, E. Fanning, R. Woodgate, and S. C. West, "Human DNA polymerase $\eta$ promotes DNA synthesis from strand invasion intermediates of homologous recombination," Molecular Cell, vol. 20, no. 5, pp. 783-792, 2005.

[21] T. Kawamoto, K. Araki, E. Sonoda et al., "Dual roles for DNA polymerase $\eta$ in homologous DNA recombination and translesion DNA synthesis," Molecular Cell, vol. 20, no. 5, pp. 793-799, 2005.

[22] S. C. Cary, T. Shank, and J. Stein, "Worms bask in extreme temperatures," Nature, vol. 391, no. 6667, pp. 545-546, 1998.

[23] D. S. Shin, M. DiDonato, D. P. Barondeau et al., "Superoxide dismutase from the eukaryotic thermophile Alvinella pompejana: structures, stability, mechanism, and insights into amyotrophic lateral sclerosis," Journal of Molecular Biology, vol. 385, no. 5, pp. 1534-1555, 2009.
[24] T. V. Burjanadze, "New analysis of the phylogenetic change of collagen thermostability," Biopolymers, vol. 53, no. 6, pp. 523$528,2000$.

[25] K. L. Henscheid, D. S. Shin, S. C. Cary, and J. A. Berglund, "The splicing factor U2AF65 is functionally conserved in the thermotolerant deep-sea worm Alvinella pompejana," Biochimica et Biophysica Acta, vol. 1727, no. 3, pp. 197-207, 2005.

[26] P. Piccino, F. Viard, P.-M. Sarradin, N. Le Bris, D. Le Guen, and D. Jollivet, "Thermal selection of PGM allozymes in newly founded populations of the thermotolerant vent polychaete Alvinella pompejana," Proceedings of the Royal Society B, vol. 271, no. 1555, pp. 2351-2359, 2004.

[27] T. Murata, S. Iwai, and E. Ohtsuka, "Synthesis and characterization of a substrate for T4 endonuclease V containing a phosphorodithioate linkage at the thymine dimer site," Nucleic Acids Research, vol. 18, no. 24, pp. 7279-7286, 1990.

[28] S. Iwai, M. Shimizu, H. Kamiya, and E. Ohtsuka, "Synthesis of a phosphoramidite coupling unit of the pyrimidine (64) pyrimidone photoproduct and its incorporation into oligodeoxynucleotides," Journal of the American Chemical Society, vol. 118, no. 32, pp. 7642-7643, 1996.

[29] J. Yamamoto, K. Hitomi, T. Todo, and S. Iwai, "Chemical synthesis of oligodeoxyribonucleotides containing the Dewar valence isomer of the (6-4) photoproduct and their use in (64) photolyase studies," Nucleic Acids Research, vol. 34, no. 16, pp. 4406-4415, 2006.

[30] S. Iwai, "Synthesis of thymine glycol containing oligonucleotides from a building block with the oxidized base," Angewandte Chemie, vol. 39, no. 21, pp. 3874-3876, 2000.

[31] T. Shimizu, K. Manabe, S. Yoshikawa, Y. Kawasaki, and S. Iwai, "Preferential formation of (5S,6R)-thymine glycol for oligodeoxyribonucleotide synthesis and analysis of drug binding to thymine glycol-containing DNA," Nucleic Acids Research, vol. 34, no. 1, pp. 313-321, 2006.

[32] B. C. Broughton, A. Cordonnier, W. J. Kleijer et al., "Molecular analysis of mutations in DNA polymerase $\eta$ in xeroderma pigmentosum-variant patients," Proceedings of the National Academy of Sciences of the United States of America, vol. 99, no. 2, pp. 815-820, 2002.

[33] H. Ling, F. Boudsocq, R. Woodgate, and W. Yang, "Crystal structure of a Y-family DNA polymerase in action: a mechanism for error-prone and lesion-bypass replication," Cell, vol. 107, no. 1, pp. 91-102, 2001.

[34] M. Bienko, C. M. Green, N. Crosetto et al., "Ubiquitinbinding domains in Y-family polymerases regulate translesion synthesis," Science, vol. 310, no. 5755, pp. 1821-1824, 2005.

[35] S. Sabbioneda, C. M. Green, M. Bienko, P. Kannouche, I. Dikic, and A. R. Lehmann, "Ubiquitin-binding motif of human DNA polymerase $v$ is required for correct localization," Proceedings of the National Academy of Sciences of the United States of America, vol. 106, no. 8, p. E20, 2009.

[36] N. Acharya, J.-H. Yoon, H. Gali et al., "Reply to sabbioneda et al.: Role of ubiquitin-binding motif of human DNA polymerase $v$ in translesion synthesis," Proceedings of the National Academy of Sciences of the United States of America, vol. 106, no. 8, p. E21, 2009.

[37] L. Haracska, R. E. Johnson, I. Unk et al., "Physical and functional interactions of human DNA polymerase $\eta$ with PCNA," Molecular and Cellular Biology, vol. 21, no. 21, pp. 7199-7206, 2001.

[38] P. L. Kannouche, J. Wing, and A. R. Lehmann, "Interaction of human DNA polymerase $\eta$ with monoubiquitinated PCNA: 
a possible mechanism for the polymerase switch in response to DNA damage," Molecular Cell, vol. 14, no. 4, pp. 491-500, 2004.

[39] E. Ohashi, T. Ogi, R. Kusumoto et al., "Error-prone bypass of certain DNA lesions by the human DNA polymerase $\kappa$," Genes and Development, vol. 14, no. 13, pp. 1589-1594, 2000.

[40] A. Tissier, E. G. Frank, J. P. McDonald, S. Iwai, F. Hanaoka, and R. Woodgate, "Misinsertion and bypass of thymine-thymine dimers by human DNA polymerase ı," EMBO Journal, vol. 19, no. 19 , pp. 5259-5266, 2000.

[41] P. D. Hoffman, M. J. Curtis, S. Iwai, and J. B. Hays, "Biochemical evolution of DNA polymerase $\eta$ : properties of plant, human, and yeast proteins," Biochemistry, vol. 47, no. 16, pp. 4583-4596, 2008.

[42] R. E. Johnson, L. Haracska, S. Prakash, and L. Prakash, "Role of DNA polymerase $\eta$ in the bypass of a (6-4) TT photoproduct," Molecular and Cellular Biology, vol. 21, no. 10, pp. 3558-3563, 2001.

[43] R. E. Johnson, M. T. Washington, S. Prakash, and L. Prakash, "Fidelity of human DNA polymerase $\eta$," Journal of Biological Chemistry, vol. 275, no. 11, pp. 7447-7450, 2000.

[44] T. Matsuda, K. Bebenek, C. Masultanl, F. Hanaoka, and T. A. Kunkel, "Low fidelity DNA synthesis by human DNA polymerase- $\eta$," Nature, vol. 404, no. 6781, pp. 1011-1013, 2000.

[45] B. J. Campbell, J. L. Stein, and S. C. Cary, "Evidence of chemolithoautotrophy in the bacterial community associated with Alvinella pompejana, a hydrothermal vent polychaete," Applied and Environmental Microbiology, vol. 69, no. 9, pp. 5070-5078, 2003.

[46] S. C. Cary, M. T. Cottrell, J. L. Stein, F. Camacho, and D. Desbruyères, "Molecular identification and localization of filamentous symbiotic bacteria associated with the hydrothermal vent annelid Alvinella pompejana," Applied and Environmental Microbiology, vol. 63, no. 3, pp. 1124-1130, 1997.

[47] F. Boudsocq, S. Iwai, F. Hanaoka, and R. Woodgate, "Sulfolobus solfataricus P2 DNA polymerase IV (Dp04): an archaeal DinB-like DNA polymerase with lesion-bypass properties akin to eukaryotic poln," Nucleic Acids Research, vol. 29, no. 22, pp. 4607-4616, 2001.

[48] J. P. McDonald, A. Hall, D. Gasparutto, J. Cadet, J. Ballantyne, and R. Woodgate, "Novel thermostable Y-family polymerases: applications for the PCR amplification of damaged or ancient DNAs," Nucleic Acids Research, vol. 34, no. 4, pp. 1102-1111, 2006.

[49] J. T. Beatty, J. Overmann, M. T. Lince et al., "An obligately photosynthetic bacterial anaerobe from a deep-sea hydrothermal vent," Proceedings of the National Academy of Sciences of the United States of America, vol. 102, no. 26, pp. 9306-9310, 2005.

[50] F. Pradillon, B. Shillito, C. M. Young, and F. Gaill, "Developmental arrest in vent worm embryos," Nature, vol. 413, no. 6857, pp. 698-699, 2001.

[51] H. Ling, F. Boudsocq, R. Woodgate, and W. Yang, "Snapshots of replication through an abasic lesion: structural basis for base substitutions and frameshifts," Molecular Cell, vol. 13, no. 5, pp. 751-762, 2004.

[52] S. Shachar, O. Ziv, S. Avkin et al., "Two-polymerase mechanisms dictate error-free and error-prone translesion DNA synthesis in mammals," EMBO Journal, vol. 28, no. 4, pp. 383393, 2009. 

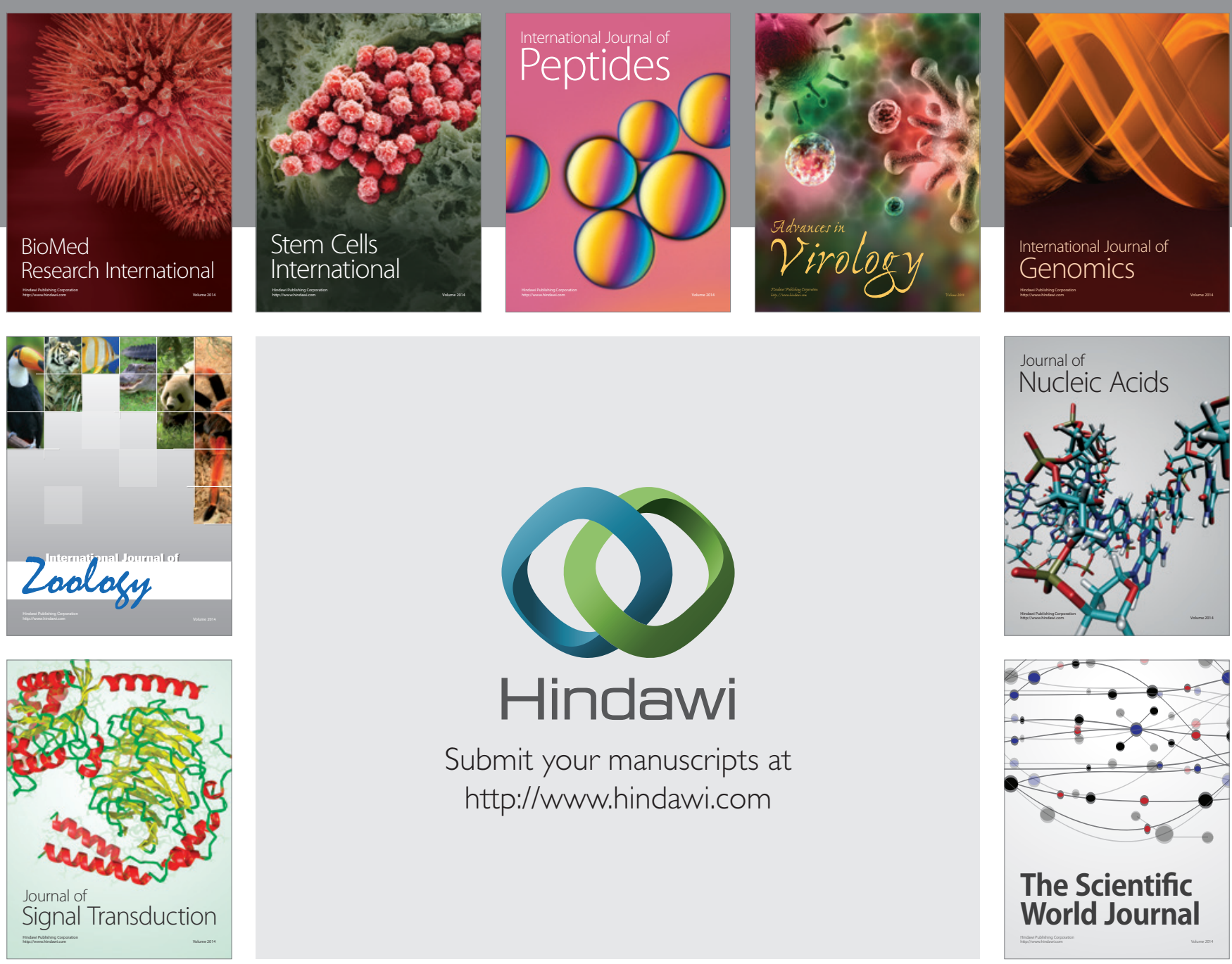

Submit your manuscripts at

http://www.hindawi.com
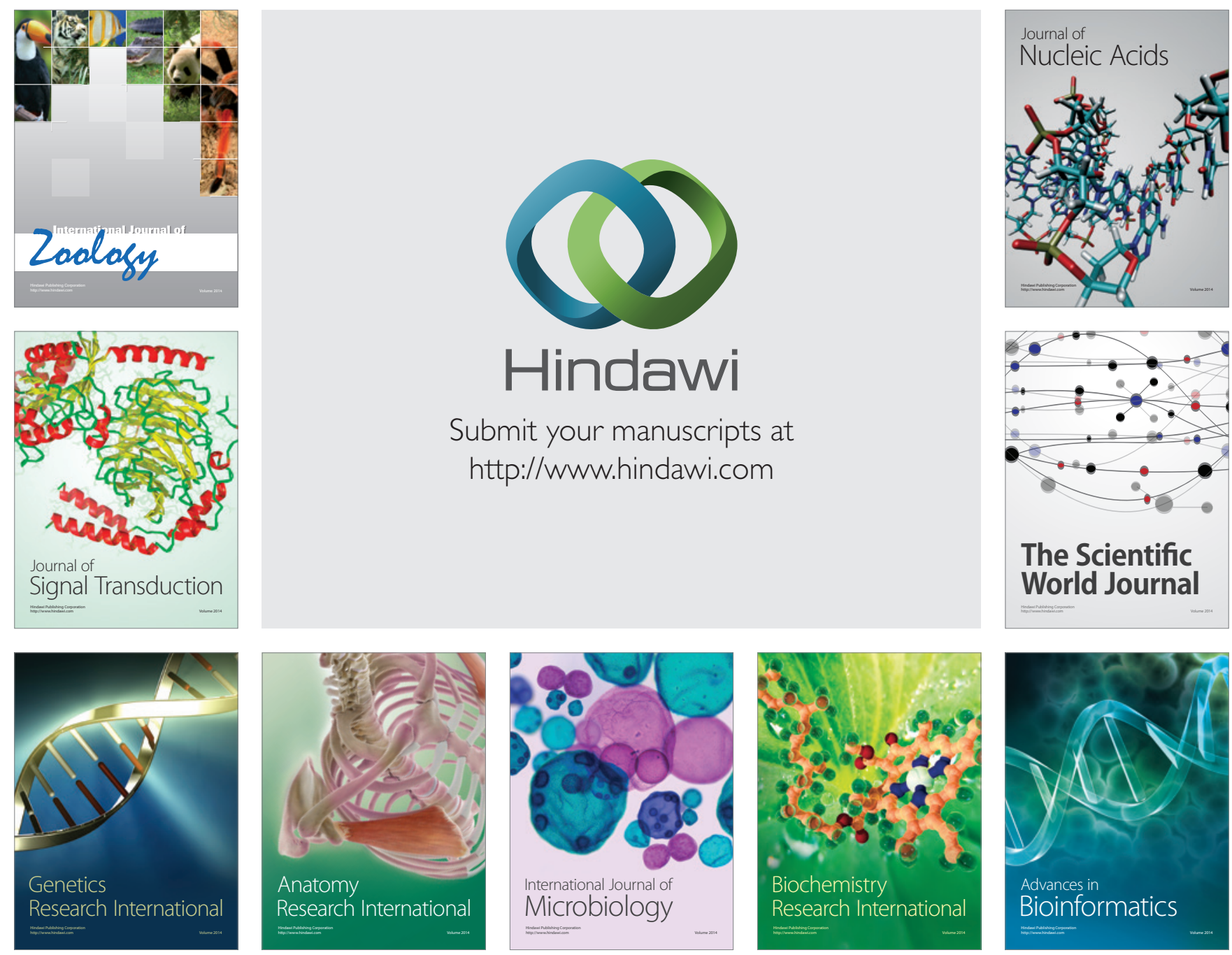

The Scientific World Journal
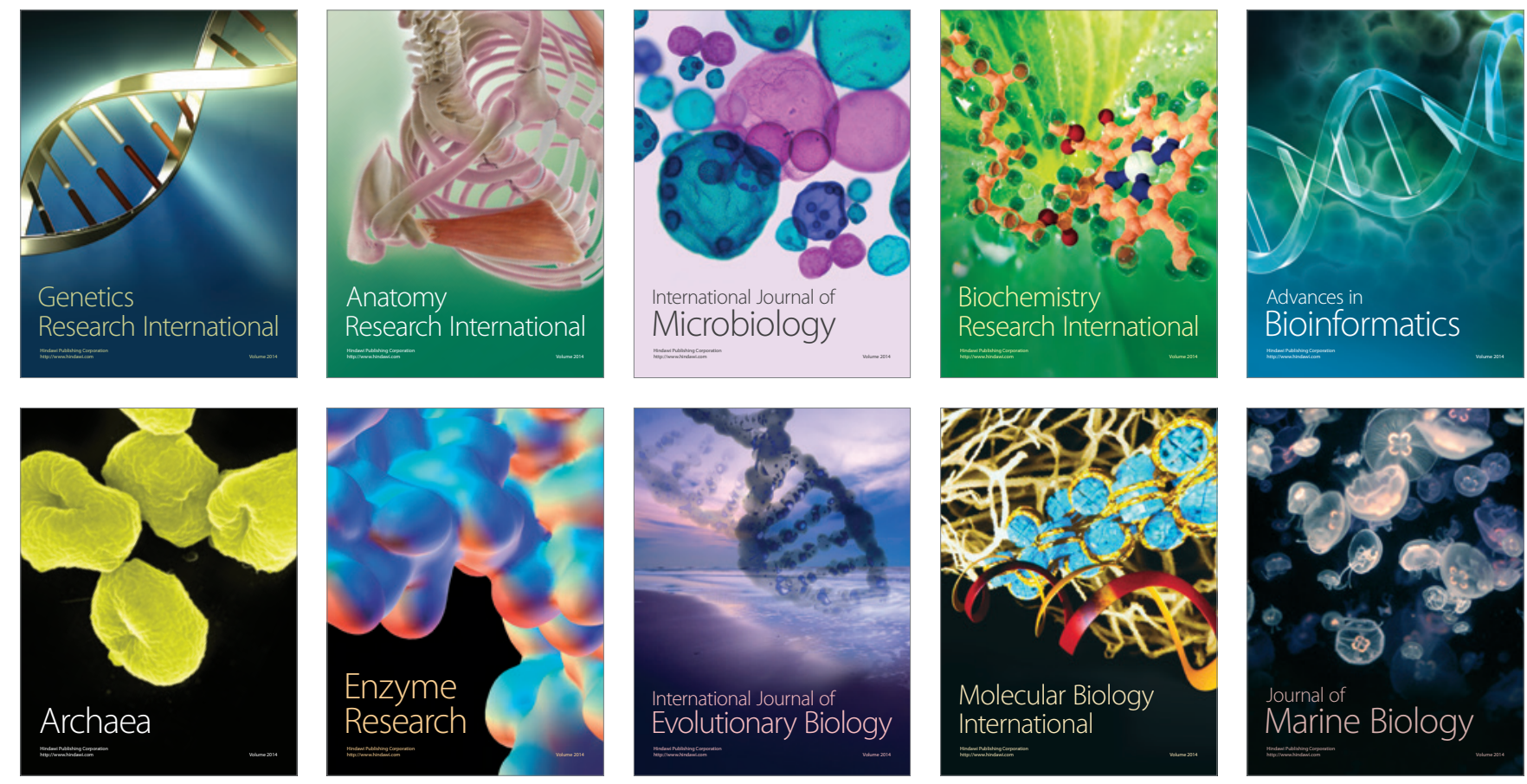